\title{
ĐÁNH GIÁ HIỆU QUẢ ĐIỀU TRỊ KHÁNG ĐÔNG Ở BỆNH NHÂN SAU THAY VAN TIM CO HỌC TẠI BỆNH VIỆN TIM TÂM ĐỨC
}

\author{
Phạm Hoàng Trọng Hiếu**, Nguyễn Hoàng Định ${ }^{*}$
}

\section{TÓM TẮT:}

Mỏ đầu: Bệnh nhân sau thay van tim cơ học cần phải được điều trị bằng thuốc kháng đông kháng vitamin $\mathrm{K}$ suốt đời. Tuy nhiên, việc điều trị bằng thuốc kháng đông gặp phải hai vấn đề chính là khoảng điều trị hẹp và hiệu quả của thuốc thay đổi bởi nhiều yếu tố như chế độ ăn, sự tương tác thuốc và sự tuân thủ điều trị,,... Vì thế, kiến thức bệnh nhân về thuốc kháng đông rất quan trọng đối với hiệu quả điều trị kháng đông.

Muc tiêu: (1) Đánh giá kết quả điều trị kháng đông bằng thuốc kháng vitamin $\mathrm{K}$ ở bệnh nhân sau thay van tim cơ học. (2) Đánh giá mối tương quan giữa sự hiểu biết của bệnh nhân về thuốc kháng đông kháng VTK với hiệu quả điều trị kháng đông bằng thuốc kháng VTK ở bệnh nhân sau thay van tim cơ học.

Đối tựng - phuơng pháp nghiên cứu: Nghiên cứu mô tả và phân tích, cắt ngang trên 200 bệnh nhân sau thay van tim cơ học tại bệnh viện Tâm Đức .

Kết quả: Qua 200 bệnh nhân trong cuộc nghiên cứu, bệnh nhân nam chiếm tỷ lệ $35,5 \%$, tuổi trung bình: $53.1+/-9.7$. Bệnh nhân thay van hai lá chiếm tỷ lệ nhiều nhất $47,5 \%$. Liều thuốc kháng đông trung bình/tuần đối với wafarin là $26,54+/-8,27 \mathrm{mg}$, đối với acenocoumarol là 11,71+/-2,1. 53\% bệnh nhân đạt INR trong ngưỡng điều trị, biến chứng chảy máu chiếm tỷ lệ 14,5\%. Đối với sự hiểu biết của bệnh nhân về thuốc kháng đông: $18 \%$ bệnh nhân có kiến thức tốt về thuốc kháng đông và có mối tương quan thuận giữa kiến thức bệnh nhân với hiệu quả điều trị kháng đông.

Kết luận: Trong nghiên cứu của chúng tôi cho thấy kiến thức của bệnh nhân về thuốc kháng đông còn thấp. Vì vậy, chúng ta cần xây dựng chương trình giáo dục sức khỏe cho bệnh nhân nhằm nâng cao kiến thức của họ về nguy cơ và cách phòng ngừa các biến chứng.

Tù khóa: INR (International Normalized Ratio), thuốc kháng Vitamin K (Vitamin K Antagonist, VKA), kiến thức bệnh nhân

\section{EFFECTIVENESS OF ORAL ANTICOAGULATIONIN PATIENTS WITH MECHANICAL HEART VALVE REPLACEMENT AT TAM DUC HEART HOSPITAL}

\section{ABSTRACT:}

Background: Patients with mechanical heart valve prostheses need lifelong oral anticoagulation therapy to prevent thrombosis. However, oral anticoagulation has a narrow therapeutic window and has been associated with many drug-drug, drug-food interactions and the importance of strict adherence.Therefore, the patient's knowledge of this drug is so important for effectiveness of oral anticoagulation

Objectives: (1) To evaluate the effectiveness of oral anticoagulationin patients with mechanical heart valve replacement; (2)To evaluate patients' knowledge of oral anticoagulation and its relationship to anticoagulation control.

Methods:observational and analytical, crosssectional study in 200 patients with mechanical heart valve replacement at Tam Duc Heart hospital.

Result:Total of 200 patients was included in the study. Sixty-nine patients $(35.5 \%)$ were males. The mean age was $53.1 \pm 9.7$ years. Mitral valve replacement was the most common indication for surgery $(47.5 \%)$. The mean cumulative weekly dose of warfarin was $26.54 \pm 8.27 \mathrm{mg}$ and of acenocoumarol was $11,71 \pm 2,1 \mathrm{mg}$. Fifty-three percent patients $(53 \%)$ achieved therapeutic INR, the bleeding complication rate was $14.5 \%$. Of the 200 patients, $18 \%$ presented good knowledge, and there was a positive correlation between patients' warfarin knowledge and the INR values that was within the target range.

Conclusion: Patients' knowledge of oral anticoagulationwas generally poor.Health education

\footnotetext{
Bệnh viện Đại học Y Duoọc TPHCM

** Bệnh viện Tâm Đức TPHCM

Nguòi chịu trách nhiệm khoa học: TS. Nguyễn Hoàng Định

Ngày nhận bài: 10/01/2016 - Ngày Cho Phép Đăng: 24/02/2016

Phản Biện Khoa học: PGS.TS. Đặng Ngoc Hùng

GS.TS. Bùi Đúc Phú
} 
must be given to patients to increase their knowledge regarding risk and prevention of complications in outpatient department and ward settings.

Key words: INR, Vitamin K Antagonist, patient knowledge.

\section{MỞ ĐÀ̀}

Vào đầu thập niên 60 , sự ra đời của van tim nhân tạo là một bước tiến quan trọng trong lĩnh vực tim mạch. Trong suốt thời gian qua, kỹ thuật thay van tim, công nghệ chế tạo các loại van tim nhân tạo không ngừng được cải tiến và số lượng bệnh nhân thay van tim nhân tạo ngày càng tăng [7]. Bệnh nhân sau thay van tim cơ học phải được điều trị kháng đông suốt đời bằng thuốc kháng Vitamin $\mathrm{K}$ để đạt chỉ số chuẩn hóa quốc tế (INR: International Normalized Ratio) 2,5 - 3,5 nhằm tránh nguy cơ huyết khối hoặc xuất huyết [13].

Hiện tại, ở Việt Nam chưa có nhiều nghiên cứu về điều trị thuốc đông kháng Vitamin $\mathrm{K}$ trên bệnh nhân sau thay van tim nhân tạo, đặc biệt là nghiên cứu về kiến thức của bệnh nhân về thuốc kháng Vitamin $\mathrm{K}$. Chúng tôi tiến hành nghiên cứu này nhằm hai mục đích:.

1. Đánh giá kết quả điều trị kháng đông bằng thuốc kháng vitamin $\mathrm{K}$ ở bệnh nhân sau thay van tim cơ học.

2. Đánh giá mối tương quan giữa sự hiểu biết của bệnh nhân về thuốc kháng đông kháng Vitamin $\mathrm{K}$ với hiệu quả điều trị kháng đông bằng thuốc kháng Vitamin $\mathrm{K}$ ở bệnh nhân sau thay van tim cơ học.

\section{2. ĐỐI TƯợNG - PHƯƠNG PHÁP NGHIÊN CÚU}

2.1. Đối tượng nghiên cứu: 200 bệnh nhân sau mổ thay van tim cơ học đang điều trị ngoại trú tại bệnh viện tim Tâm Đức Hồ Chí Minh có dùng thuốc kháng đông kháng Vitamin $\mathrm{K}$.

Tiêu chuẩn chọn lựa: bệnh nhân sau mổ thay van tim cơ học từ 6 tháng trở lên, tái khám đúng hẹn và uống thuốc đều theo toa. Loại trừ những bệnh nhân có thai, bệnh nhân hoặc người đại diện pháp lý không đồng ý tham gia nghiên cứu.

\subsection{Phương pháp nghiên cứu:}

- Nghiên cứu mô tả và phân tích, cắt ngang.

- Tiêu chí đánh giá: Chỉ số INR đạt mục tiêu điều trị dưa vào khuyến cáo của $\mathrm{AHA} / \mathrm{ACC}$ (American Heart Association/ American College Cardiology) [6] và $\mathrm{ESC}$ (European Society Cardiology) [13] về mức giá trị INR cho từng bệnh nhân sau thay van tim cơ học. Hiểu biết của bệnh nhân được đánh giá qua 8 câu hỏi được xây dựng từ bộ câu hỏi kiến thức về thuốc kháng đông kháng VTK của tác giả Helena Teixeira
Rocha [8] và Sara Van Damme [14], gồm hai giá trị kiến thức đúng và kiến thức chưa đúng (sai hoặc không biết) và được phân theo 3 mức độ: kiến thức cao (trả lời đúng $>80 \%$ bộ câu hỏi), kiến thức trung bình (trả lời đúng $50-80 \%$ bộ câu hỏi), kiến thức thấp (trả lời đúng dưới $50 \%$ bộ câu hỏi).

- Tiến hành: Bệnh nhân thay van tim cơ học đến tái khám thỏa tiêu chuẩn chọn mẫu, được bác sĩ thu thập thông tin, hỏi bệnh, khám lâm sàng, thu thập số liệu về cận lâm sàng, phỏng vấn bệnh nhân.

Xư lý số liệu: Các số liệu được xử lý theo thuật toán thống kê $\mathrm{y}$ học bằng Excel và phần mềm SPSS 20.0 để phân tích số liệu. Các số liệu biến định tính được trình bày dưới dạng tỷ lệ phần trăm. Đánh giá thang đo kiến thức bệnh nhân về thuốc kháng đông kháng VTK bằng hệ số Cronbach's alpha. Các biến định lượng, kết quả được trình bày theo giá trị trung bình \pm độ lệch chuẩn, giá trị lớn nhất, giá trị nhỏ nhất, tỷ lệ phần trăm. So sánh sự khác biệt giữa hai tỷ lệ dùng test chi bình phương (hoặc $\mathrm{T}$ test). Sự khác biệt có ý nghĩa thống kê với $\mathrm{p}<0,05$.

\section{KẾT QUẢ}

\section{1. Đặc điểm bệnh nhân:}

Có 200 bệnh nhân được tuyển chọn vào nghiên cứu. Đặc điểm bệnh nhân được trình bày ở bảng 1 . Tuổi trung bình (năm) là $53,1 \pm 9,7$; tỷ lệ nam giới chiếm $34,5 \%$; van cơ học gồm $47,5 \%$ van hai lá, $16 \%$ van động mạch chủ và $36,5 \%$ van hai lá kèm van động mạch chủ; $80 \%$ bệnh nhân dùng thuốc kháng đông kháng Vitamin K loại Wafarin và $20 \%$ bệnh nhân dùng loại Acenocoumarol.

\begin{tabular}{|l|c|c|}
\hline \multicolumn{1}{|c|}{ Đặc điểm } & Giá trị & $\begin{array}{c}\text { Khoảng } \\
\text { biến thiên }\end{array}$ \\
\hline Tuổi (năm) & $53,1 \pm 9,7$ & $27-76$ \\
\hline Giới (n,\%) & $69(34,50 \%)$ & \\
\hline Nam & $131(65,50 \%)$ & \\
\hline Nữ & $23,08 \pm 2,97$ & $15,6-32$ \\
\hline BMI & $160(80,00 \%)$ & \\
\hline $\begin{array}{l}\text { Loại thuốc kháng } \\
\text { Vitamin K }\end{array}$ & \multicolumn{2}{|l}{} \\
\hline Acenocoumarol & $40(20,00 \%)$ & \\
\hline Wafarin & $95(47,50 \%)$ & \\
\hline Loại van cơ học (n, \%) & \multicolumn{2}{|l|}{} \\
\hline Van hai lá & $32(16,00 \%)$ & \\
\hline Van động mạch chủ & $73(36,50 \%)$ & \\
\hline $\begin{array}{l}\text { Van hai lá + Van } \\
\text { động mạch chủ }\end{array}$ & \\
\hline
\end{tabular}




\subsection{Kết quả xét nghiệm INR:}

Qua phân tích kết quả xét nghiệm INR cắt ngang, đối chiếu kết quả của từng bệnh nhân với các đặc điểm cụ thể như vị trí van, số lượng van và các yếu tố nguy cơ tăng đông, chúng tôi nhận thấy có $53 \%$ bệnh nhân đạt INR trong mục tiêu điều trị, $21 \%$ bệnh nhân dưới mục tiêu điều trị và $26 \%$ bệnh nhân trên mục tiêu điều trị. $77 \%$ bệnh nhân có xét nghiệm INR nằm trong khoảng tương đối an toàn $(2,0-4,0)$.

Liều thuốc kháng đông trung bình đối với bệnh nhân dùng acenocoumarol là $11,7 \pm 2,1 \mathrm{mg} /$ tuần và đối với wafarin là $26,54 \pm 8,27 \mathrm{mg} /$ tuần. Có mối tương quan giữa liều $\mathrm{TB} /$ tuần của thuốc kháng đông kháng
VTK loại Acenocoumarol với cân nặng của bệnh nhân $(\mathrm{r}=0,37 ; \mathrm{p}=0,01)$.

Tỷ lệ bệnh nhân trong nghiên cứu của chúng tôi có biến chứng chảy máu hay huyết khối thuyên tắc chiếm $14,5 \%$. Có sự gia tăng tỷ lệ biến chứng chảy máu theo sự tăng lên của mức INR $(p<0,05)$. Không có sự khác biệt về liều TB/tuần của các thuốc kháng đông giữa hai nhóm có biến chứng và không có biến chứng.

Tỷ lệ INR trong mục tiêu của thuốc kháng đông kháng VTK loại Acenocoumarol (62,5\%) cao hơn so với Wafarin $(50,6 \%)$, nhưng sự khác biệt này không có ý nghĩa thống kê $(p=0,18)$.

Bảng 2. Thuốc và liều các thuốc kháng đông kháng Vitamin K

\begin{tabular}{|c|c|c|c|c|c|}
\hline \multirow{2}{*}{ Loại thuốc } & $\mathbf{N}$ & \multicolumn{3}{|c|}{ Liều thuốc/tuần (mg) } & INR \\
\hline & $\%$ & $\bar{X} \pm S D$ & Liều thấp nhất & Liều cao nhất & $\bar{X} \pm S D$ \\
\hline \multirow{2}{*}{ Acenocoumarol } & 40 & \multirow{2}{*}{$11,71 \pm 2,10$} & \multirow{2}{*}{6} & \multirow{2}{*}{15} & \multirow{2}{*}{$3,20 \pm 0,92$} \\
\hline & $20,0 \%$ & & & & \\
\hline \multirow{2}{*}{ Wafarin } & 160 & \multirow{2}{*}{$26,54 \pm 8,27$} & \multirow{2}{*}{12} & \multirow{2}{*}{50} & \multirow{2}{*}{$3,05 \pm 1,21$} \\
\hline & $80,0 \%$ & & & & \\
\hline
\end{tabular}

Bảng 3. Liên quan giữa INR ngoài mục tiêu và các thuốc kháng VTK

\begin{tabular}{|l|c|c|c|c|}
\hline \multicolumn{1}{|c|}{ Thuốc } & $\begin{array}{c}\text { Tỷ lệ INR ngoài mục } \\
\text { tiêu/n (\%) }\end{array}$ & $\begin{array}{c}\text { Tỷ lệ INR trong mục } \\
\text { tiêu/n (\%) }\end{array}$ & $\begin{array}{c}\text { Tổng } \\
\mathbf{n}(\%)\end{array}$ & P \\
\hline Acenocoumarol & $15(7,5 \%)$ & $25(12,50 \%)$ & $40(20 \%)$ & \\
\cline { 1 - 4 } Wafarin & $79(39,50 \%)$ & $81(40,50 \%)$ & $160(80 \%)$ & \multirow{2}{*}{0,18} \\
\cline { 1 - 4 } Tổng & $94(47 \%)$ & $106(53 \%)$ & $200(100 \%)$ & \\
\hline
\end{tabular}

Bảng 4. Tỷ lệ biến chúng chảy máu theo các mức INR

\begin{tabular}{|c|c|c|c|c|}
\hline \multirow{2}{*}{ Mức INR } & \multicolumn{2}{|c|}{ Biến chứng chảy máu } & \multirow{2}{*}{ Tổng } & \multirow{2}{*}{$\mathbf{P}$} \\
\hline & Có - n (\%) & Không - n (\%) & & \\
\hline$<3,5$ & $13(8,55 \%)$ & $139(91,45 \%)$ & 152 & \multirow{3}{*}{$<0,05$} \\
\hline $3,5-5,0$ & $11(28,95 \%)$ & $27(71,05 \%)$ & 38 & \\
\hline$>\mathbf{5 , 0}$ & $5(50,00 \%)$ & $5(50,00 \%)$ & 10 & \\
\hline
\end{tabular}




\subsection{Kiến thức của bệnh nhân về thuốc kháng đông}

$18 \%$ bệnh nhân có kiến thức cao, $62 \%$ bệnh nhân có kiến thức trung bình và $20 \%$ bệnh nhân có kiến thức thấp về thuốc kháng đông.

Tỷ lệ INR ngoài mục tiêu ở nhóm bệnh nhân có kiến thức thấp về thuốc kháng đông cao hơn so với ở nhóm bệnh nhân có kiến thức cao về thuốc kháng đông. Sự khác biệt này có ý nghĩa thống kê $(\mathrm{p}<0,05)$.

\section{Bảng 5. Tỷ lệ kiến thức đúng về thuốc kháng đông đối với tù̀ng câu hỏi}

\begin{tabular}{|l|c|c|}
\hline \multicolumn{1}{|c|}{ Câu hỏi } & $\begin{array}{c}\text { Đúng } \\
\text { (\%) }\end{array}$ & $\begin{array}{c}\text { Sai, không } \\
\text { biết(\%) }\end{array}$ \\
\hline $\begin{array}{l}\text { Q1. Bệnh nhân biết vấn đề ăn nhiều rau xanh (bắp cải, rau cải, bông cải xanh, } \\
\text { rau diếp...) hoặc gan heo, gan bò,... làm giảm hiệu quả của thuốc kháng đông. }\end{array}$ & $29,5 \%$ & $71,5 \%$ \\
\hline $\begin{array}{l}\text { Q2. Bệnh nhân biết vấn đề uống nhiều rượu bia (> 2 ly) làm tăng nguy cơ chảy } \\
\text { máu. }\end{array}$ & $39,5 \%$ & $60,5 \%$ \\
\hline Q3. Bệnh nhân biết liều thuốc kháng đông đang dùng. & $87 \%$ & $13 \%$ \\
\hline Q4. Bệnh nhân biết xét nghiệm INR là để kiểm tra hiệu quả thuốc kháng đông & $83 \%$ & $17 \%$ \\
\hline Q5. Bệnh nhân biết giá trị xét nghiệm PT/INR cần đạt. & $55 \%$ & $45 \%$ \\
\hline Q6. Bệnh nhân biết khi quên uống 01 liều thuốc kháng đông sẽ ảnh hưởng đến hiệu \\
quả của thuốc kháng đông.
\end{tabular}

Bảng 6. Tỷ lệ INR ngoài mục tiêu theo các mức kiến thức chung đúng của bệnh nhân về thuốc kháng đông

\begin{tabular}{|l|c|c|c|}
\hline \multirow{2}{*}{ Kiến thức chung đúng } & $\begin{array}{c}\text { INR trong mục tiêu } \\
\mathbf{n}(\%)\end{array}$ & $\begin{array}{c}\text { INR ngoài mục tiêu } \\
\mathbf{n}(\%)\end{array}$ & \multirow{2}{*}{$<0,05$} \\
\hline Thấp & $9(4,5 \%)$ & $31(15,5 \%)$ & \\
\hline Cao & $32(16 \%)$ & $4(2 \%)$ & $<$ \\
\hline
\end{tabular}

\section{BÀN LUẪN}

Các bệnh nhân trong nghiên cứu của chúng tôi có độ tuổi trung bình $53,15 \pm 9,74$ (năm), tỷ lệ thay van hai lá đơn thuần chiếm cao nhất $(47,5 \%)$. Các kết quả này tương tự như kết quả nghiên cứu của một số nước Châu Á khác [12][16], nơi mà bệnh lý van tim dẫn 
đến thay van chủ yếu là do hậu thấp; trong khi ở các nước Châu Âu và Bắc Mỹ, bệnh lý van tim dẫn đến thay van chủ yếu là do thoái hóa van [3][15].

$80 \%$ bệnh nhân trong nghiên cứu của chúng tôi dùng thuốc kháng đông kháng VTK loại Wafarin với liều trung bình là 26,54 $\pm 8,27 \mathrm{mg} /$ tuần, tương tự như kết quả nghiên cứu của tác giả Suwanawiboon $\mathrm{B}$ và cộng sự (Thái Lan) được thực hiện trên 164 bệnh nhân, có liều wafarin trung bình là 22,3 $\pm 5,8 \mathrm{mg} /$ tuần [10].

Tỷ lệ INR đạt mục tiêu trong nghiên cứu của chúng tôi là $53 \%$, thấp hơn so với các nghiên cứu ở Châu Âu và Bắc Mỹ(tỷ lệ INR đạt mục tiêu thấp nhất là $55-60 \%$ nếu chống đông được quản lý bởi bác sĩ đa khoa và cao nhất lên đến $80 \%$ nếu bệnh nhân được giáo dục tốt) [1][3][9]. Kết quả này nói lên thực trạng điều trị và giám sát điều trị kháng đông ở bệnh nhân sau thay van tim ở Việt Nam còn nhiều thách thức.

Tỷ lệ biến chứng chảy máu trong nghiên cứu của chúng tôi là $14,5 \%$, có sự gia tăng biến chứng chảy máu theo sự tăng lên của mức INR. Theo nhiều nghiên cứu, khi điều trị chống đông bằng thuốc kháng vitamin $\mathrm{K}$ thì INR là yếu tố quan trọng nhất liên quan đến biến chứng chảy máu, tỷ lệ chảy máu tăng khi INR $>3,5$ và tăng lên cấp số nhân khi INR > 5,0 [2][3].

Trong nghiên cứu của chúng tôi, tỷ lệ bệnh nhân có kiến thức cao về thuốc kháng đông là $18 \%$, tương tự như của tác giả Sara Van Damme là $15,7 \%$ [14] và $11 \%$ của tác giả Laila $M$ Matalqah[5]. Có mối tương quan thuận giữa kiến thức bệnh nhân về thuốc kháng đông với kết quả xét nghiệm INR trong mục tiêu. Kết quả của chúng tôi tương tự như kết quả nghiên cứu của tác giả Tang E.O.Y và cộng sự [11] cho thấy có mối tương quan giữa kiến thức về thuốc và số lượng các giá trị INR trong phạm vi mục tiêu ở 4 lần xét nghiệm gần nhất $(\mathrm{r}=0,20 ; \mathrm{p}=0,024)$. Ngoài $\mathrm{ra}$, một nghiên cứu thử nghiệm tương tự tại Nhật Bản của Landefeld C.S [4] và cộng sự cũng cho thấy nhóm được tư vấn và hướng dẫn tốt về chế độ ăn và dùng thuốc có tỷ lệ đạt INR mục tiêu $52 \%$ cao hơn so với $45 \%$ ở nhóm quản lý thông thường.

\section{KẾT LUẬN}

Tỷ lệ INR đạt mục tiêu điều trị trong nghiên chúng của chúng tôi còn tương đối thấp so với các nước Châu Âu và Bắc Mỹ, do đó chúng ta cần phải nâng tỷ lệ INR đạt mục tiêu lên cao hơn nữa.

Tỷ lệ bệnh nhân có kiến thức cao về thuốc kháng đông trong nghiên cứu của chúng tôi còn thấp. Do đó, chúng ta cần có các chương trình giáo dục người bệnh các kiến thức về thuốc kháng đông, chế độ ăn uống ảnh hưởng lên thuốc kháng đông và giám sát chặt chẽ sự tuân thủ của bệnh nhân để đạt hiệu quả điều trị kháng đông tốt nhất.

\section{TÀI LIỆU THAM KHẢO}

1. Arbring K, Uppugunduri S, Lindahl T.L (2013), "Comparison of prothrombin time (INR) results and main characteristics of patients on warfarin treatment in primary health care centers and anticoagulation clinics", BMC Health Serv Res, 13 , pp. 85.

2. Cannegieter S.C, Rosendaal F.R, Wintzen, et al (1995), "Optimal oral anticoagulant therapy in patients with mechanical heart valves", $N$ Engl $J$ Med, 333(1), pp. 11-17.

3. Koertke H, Zittermann A, Tenderich G, et al (2007), "Low-dose oral anticoagulation in patients with mechanical heart valve prostheses: final report from the early self-management anticoagulation trial II", Eur Heart J, 28(20), pp. 2479-2484.

4. Landefeld C.S, Anderson P.A (1992), "Guidelinebased consultation to prevent anticoagulantrelated bleeding. A randomized, controlled trial in a teaching hospital", Ann Intern Med, 116(10), pp. 829-837.

5. Matalqah L.M, Radaideh K.M, Sulaiman S.A.S, et al (2013), "Relationship between patients' 
warfarin knowledge and anticoagulation control: results of a validated tool in Malaysia", Pharm Biomed Sci, 30(30), pp. 967-974.Nishimura RA, Otto CM, Bonow RO, et al (2014), “2014 AHA/ACC Guideline for the Management of Patients With Valvular Heart Disease: executive summary: a report of the American College of Cardiology/American Heart Association Task Force on Practice Guidelines", Circulation, 29 (23), pp. 2440-2492.

6. Phạm Nguyễn Vinh (2012), "Van tim nhân tạo", Bệnh van tim chuẩn đoán và điều trị, Nhà xuất bản y học, tr. 335-361.

7. Rocha HT, Rabelo ER, Aliti G, et al (2010), "Knowledge of Patients with Mechanical Valve Prostheses Concerning Chronic Oral Anticoagulant Therapy", Rev Lat Am Enfermagem, 18(4), pp.696-702.

8. Shaff I.W, Giuliani E.R, Oersh B.J, et al (1996), "Prosthetic Valves", Mayo Clinic Practice of Cardiology, 3rd ed. St. Louis: Mosby, pp. 1484-1495.
9. Suwanawiboon B, Kongtim P, Chinthammitr Y, Ruchutrakool T, Wanachiwanawin W (2011), "The efficacy of 3-mg warfarin initiating dose in adult Thai patients, who required long-term anticoagulant therapy", JMed Assoc Thai, 94, pp. 225-231.

10. Tang E.O.Y, Lai C.S, Lee K.K, et al (2003), "Relationship between patients' warfarin knowledge and anticoagulation cotrol", Ann Pharmacother, 37 (1), pp. 34- 39.

11. Tayyebikhosroshahi H, Sanaat Z, Farhoudi M, et al (2011), "Warfarin maintenance dose in Iranian patients", Neurosciences, 16, pp. 125-128.

12. Vahanian A, Alfieri O, Andreotti F, et all (2012), "Guidelines on the management of valvular heart Disease ", Eur Heart J, 33 (19), pp. 2451-2496.

13. Van Damme S, Van Deyk K, Budts W, et al (2011), "Patientknowledge of and adherence to oral anticoagulation therapy after mechanical heart-valve replacement for congenital or acquired valve defects", Heart\& Lung, 40 (2), pp.139-146.

14. Van Nooten G.J, Caes F, Francoi K, et al (2012), "Twenty years' single-center experience with mechanical heart valves: a critical review of anticoagulation policy", $J$ Heart Valve Dis, 01, pp. 88-98.

15. Yu H.C, Chan T.Y, Crittchley J.A, Woo K.S, et al (1996), " Factors determining the maintenance dose of warfarin in Chinese patients", $Q J M, 89$, pp. 127-135. 